\title{
Active Bilayer PE/PCL Films for Food Packaging Modified with Zinc Oxide and Casein
}

\author{
Ana Rešček, ${ }^{1, *}$ Ljerka Kratofil Krehula,, ${ }^{2, *}$ Zvonimir Katančić, ${ }^{2}$ Zlata Hrnjak-Murgić ${ }^{2}$
}

\author{
1 PIK Vrbovec d.d., Zagrebačka 148, HR-10340 Vrbovec, Croatia \\ 2 Faculty of Chemical Engineering and Technology, University of Zagreb, Marulićev trg 19, P.O. Box 177, HR-10000 Zagreb, Croatia \\ * Corresponding authors' e-mail addresses: ana.rescek@pik-vrbovec.hr, krehula@fkit.hr
}

RECEIVED: October 27, 2015 * REVISED: December 4, 2015 * ACCEPTED: December 9, 2015

THIS PAPER IS DEDICATED TO DR. SVETOZAR MUSIĆ ON THE OCCASION OF HIS 70

\begin{abstract}
This paper studies the properties of active polymer food packaging bilayer polyethylene/polycaprolactone (PE/PCL) films. Such packaging material consists of primary PE layer coated with thin film of PCL coating modified with active component (zinc oxide or zinc oxide/casein complex) with intention to extend the shelf life of food and to maintain the quality and health safety. The influence of additives as active components on barrier, mechanical, thermal and antimicrobial properties of such materials was studied. The results show that, in comparison to the neat PE and PE/PCL films, some of PE/PCL bilayer films with additives exhibit improved barrier properties i.e. decreased water vapour permeability. Higher thermal stability of modified PE/PCL material is obtained due to a modified mechanism of thermal degradation. The samples with the additive nanoparticles homogeneously dispersed in the polymer matrix showed good mechanical properties. Addition of higher $\mathrm{ZnO}$ content contributes to the enhanced antibacterial activity of a material.
\end{abstract}

Keywords: active packaging, casein, polyethylene, polycaprolactone, zinc oxide.

\section{INTRODUCTION}

N ORDER to ensure better quality, freshness and convenience of food products there is an intensive search for the proper packaging materials, which will maintain food characteristics and nutritional quality as well as health safety. For that reason packaging technologies are constantly developing and one example of modern packaging include active packaging materials. Such materials can be defined as smart systems that include interactions between packaged food and packaging components. The action of an active packaging involves different functions like indication of the contaminants migration, inhibition of the microorganisms growth and in general prevention of food spoilage end deterioration. The additives incorporated in such packaging materials make material active by their role as moisture absorbers, ethylene absorbers, oxygen scavengers, flavour releasing/absorbing systems, antimicrobial agents or temperature indicators. ${ }^{[1-3]}$

For example, in order to extend the food products shelf-life it is needed to adjust polymer packaging barrier properties to water vapour and gasses by incorporating some substances with specific properties in packaging material because inadequate barrier properties can be critical issues in food packaging. It is needed to adjust barrier properties of material with the specific properties of each food product in order to gain the best possible packaging performance with the final demand of extending the food shelflife. For example, the control of moisture level in food packages is important in order to inhibit microbial growth. The excess of water in a food package can be controlled using moisture absorbers. ${ }^{[4]}$ For that purpose multilayered composite structures and polymer blends with specific functional properties are constantly developing. ${ }^{[5]}$

Novel food packaging polymer materials based on nanotechnology can provide solutions to increase the polymers performances. ${ }^{[6-8]}$ Their use may enable environmental and economical advantages and contribute to the additional safety of food by reduction of any critical interaction with food matrices and with human health and in the same time by improving or bringing some specific properties like barrier protection to gases and liquids, antimocrobial properties, UV protection etc. Generally, the 
presence of nanoparticles plays a dynamic role in food preservation and allows packaging materials to interact with food and the environment. ${ }^{[9,10]}$ Due to their lower size, nanoparticles have larger surface area than microscale particles. For that reason the nanoscale range materials may present different mechanical, electronic, optical, barrier, catalytic and other properties. Preparation of packaging materials with incorporated nanoparticles includes several procedures like incorporation during processing (extrusion, blending in the melt). The other procedures involve coatings with nanoparticles applied onto polymer surface and the final material is then comprised of two layers.

It is known that humidity and temperature parameters are very important for food quality preservation. In general, barrier property refers to a capability of a material to resist the diffusion of a specific species atom, ion or molecule into and through the material. For a good gas and vapour barrier property the main condition is that the material is a pore-free. Various polymers can be used as selective barrier materials for the transport of water vapour and, depending on the use for packaging of different food types, a high or low permeability of water vapour is needed. For example, for fresh food (cheese, meat, fruits and vegetables) it is important to avoid dehydration while for dry food (sugar, rice, biscuits) it is important to avoid water permeation. In order to control the growth of microorganisms in food packaging and prolong the health safety and duration of food the development of antimicrobial packaging presents a possible solution. Antimicrobial polymer packaging represents a special type of an active packaging where the continuous migration of an antimicrobial substance from the packaging to the food product occurs.

This study focuses on the research of bilayer PE films coated with modified polycaprolactone (PCL) using zinc oxide $(\mathrm{ZnO})$ nanoparticles or caseine/ZnO complexes in order to gain good barrier properties and achieve antimicrobial properties but, at the same time, to maintain good mechanical and thermal properties.

\section{EXPERIMENTAL SECTION}

\section{Materials}

Commercial PE film (LDPE) with thickness of $60 \mu \mathrm{m}$, density $0.92-0.95 \mathrm{~g} / \mathrm{cm}^{3}$ and grammage $73.6 \mathrm{~g} / \mathrm{m}^{2}$ was coated with the polycaprolactone $(\mathrm{PCL})$ Sigma Aldrich, $\mathrm{Mn}=70000$ $90000 \mathrm{Da}$, density $1.145 \mathrm{~g} / \mathrm{cm}^{3}$, melting point $60^{\circ} \mathrm{C}$. As a solvent tetrahydrofuran (THF) Lach - Ner, density $0.89 \mathrm{~g} / \mathrm{cm}^{3}$, melting point $65.0-66.5^{\circ} \mathrm{C}$, was used. Used casein was obtained from Acros Organics, $\mathrm{Mn}=477.55 \mathrm{Da}$, protein content $\geq 92 \%$, density $1.25 \mathrm{~g} / \mathrm{cm}^{3}$ and used zinc oxide ( $\mathrm{ZnO}$ ) was from Lach $-\mathrm{Ner}, \mathrm{Mr}=81.39 \mathrm{Da}$, melting point $1975^{\circ} \mathrm{C}$.
Table 1. Samples of casein/ZnO complexes, $\% w / w$

\begin{tabular}{ccc}
\hline Sample & C & Zn \\
\hline C-Zn 1 & 99.0 & 1.0 \\
C-Zn 5 & 95.0 & 5.0 \\
C-Zn 10 & 90.0 & 10.0 \\
\hline C- casein, Zn-ZnO. & &
\end{tabular}

\section{Preparation of Casein Bionanocomplex}

Casein solution was prepared by dissolving $4 \mathrm{~g}$ of sodium chloride in $700 \mathrm{ml}$ of distilled water to give a $0.1 \mathrm{M}$ solution of $\mathrm{NaCl}$ to which was then gradually added $60 \mathrm{~g}$ of casein. Dissolving of casein is carried out on a magnetic stirrer at elevated temperature $\left(37-38{ }^{\circ} \mathrm{C}\right)$ until complete dissolution. In thus prepared $10 \%$ solution of casein, $\mathrm{ZnO}$ nanoparticles were added in proportions shown in Table 1. Thereafter, the samples stood for 24 hours at room temperature. The liquid layer above the sedimented solid particles was carefully separated by decantation and the remaining solution containing the solid particles was centrifuged for $15 \mathrm{~min}$ at $3000 \mathrm{rpm}$. The resulting precipitate was washed with distilled water and centrifuged again for $10 \mathrm{~min}$ at $3000 \mathrm{rpm}$. The precipitate in a Petri dish was dried in an oven at $35{ }^{\circ} \mathrm{C}$ for 6 hours and the samples were stored in the freezer.

\section{Preparation of Double Layer PE/PCL Films}

Coating layer was prepared from $\mathrm{PCL}$ polymer, containing $\mathrm{ZnO}$ or casein/ZnO bionanocomplex. For this purpose $10 \%$ solution of $\mathrm{PCL}$ was prepared in tetrahydrofuran, stirring with speed of $350 \mathrm{rpm}$ at a magnetic stirrer at room temperature. In $50 \mathrm{~mL}$ of the $\mathrm{PCL}$ solution $2 \mathrm{~g}$ of $\mathrm{ZnO}$ or casein/ZnO bionanocomplex was added and dispersed by disperser IKA T25 digital ULTRA-Turrax, for 8 minutes at a speed of $15000 \mathrm{rpm}$. On PE films $(14 \times 14 \mathrm{~cm})$ was deposited $\mathrm{PCL}$ polymer solution using the applicator Zehntner ZFR 2040 in thickness of $30 \mu \mathrm{m}$ so double layer PE/PCL films were obtained. After drying (5-7 $\mathrm{min}$ ) total thickness of double layer PE/PCL films was $63 \mu \mathrm{m}$. The final thickness of the PCL coating was $3 \mu \mathrm{m}$.

\section{Characterization}

\section{WATER VAPOUR PERMEABILITY}

Water vapour permeability determination of bilayer $\mathrm{PE} / \mathrm{PCL}$ films was carried out on the Herfeld's appliance. Herfeld's device consists of a glass container with a metal lid which contains a circular hole diameter of $36 \mathrm{~mm} .50 \mathrm{~cm}^{3}$ of water was poured into the glass vessel. On the cover of the vessel the studied sample pattern of circular diameter of $55 \mathrm{~mm}$ (face up) was set and the lid was closed. Device was placed 
in a desiccator with $97 \%$ sulphuric acid. The weight of the apparatus with the specimen and the water was determined at the beginning and after the given time interval of $24 \mathrm{~h}$ and $48 \mathrm{~h}$. Water vapour transmission (WVTR) was determined according to equation:

$$
\text { WVTR }=m_{0}-\frac{m_{2}+m_{3}}{2}
$$

$m_{0}$ - mass of the device with water and specimen at the beginning [g]

$m_{2}-$ mass of the device with water and specimen after 24 hours [g]

$m_{3}-$ mass of the device with water and specimen after 48 hours [g]

\section{SCANNING ELECTRON MICROSCOPY}

Scanning electron microscopy (SEM) was utilized to determine the morphology and the dispersibility, i.e. the distribution of nanocomposites in polycaprolactone layer using Tescan VEGA 3 SEM, 10 kV. Samples were gold-sputtered before examination.

\section{DIFFERENTIAL SCANNING CALORIMETRY}

Thermal properties of double layer PE/PCL films were determined by differential scanning calorimeter (DSC) Mettler Toledo DSC 823eT. Samples weighing approximately $10 \mathrm{mg}$ were heated from $0{ }^{\circ} \mathrm{C}$ to $140^{\circ} \mathrm{C}$, followed by a cooling cycle to $-80{ }^{\circ} \mathrm{C}$ and heating again. The measurement was conducted in a nitrogen atmosphere $\left(\mathrm{N}_{2}\right)$, at a flow rate of 50 $\mathrm{mL} / \mathrm{min}$ and at a heating rate of $10{ }^{\circ} \mathrm{C} / \mathrm{min}$. Enthalpy of melting $\left(\Delta H_{\mathrm{m}}\right)$ and crystallization $\left(\Delta H_{\mathrm{c}}\right)$, crystallization temperature $\left(T_{c}\right)$ and melting temperature $\left(T_{m}\right)$ were determined for all samples.

\section{MECHANICAL PROPERTIES}

For the testing of mechanical properties (tensile strength $\sigma$ and elongation at break $-\varepsilon$ ) of PE/PCL films universal mechanical testing machine Zwick Testing Machine (Model 1445) was used. Measurements were carried out according to ISO 527-1 and ISO 527-2 standards and the samples were prepared in dimensions $100 \times 10 \times$ film thickness (cca 60 $\mu \mathrm{m})$. A gauge length of $25 \mathrm{~mm}$ and crosshead speed of 50 $\mathrm{mm} / \mathrm{min}$ were used at a constant temperature $\left(23^{\circ} \mathrm{C}\right)$ and humidity $(50 \% \mathrm{RH})$. The results were expressed as an average value of five measurements.

\section{FTIR SPECTROSCOPY}

Modified nanofiller and nanocomposites were characterized by attenuated total reflectance Fourier transform infrared spectroscopy (ATR FTIR), Spectrum One FTIR spectrometer, Perkin Elmer, in the range from 4000 to 450 $\mathrm{cm}^{-1}$ with resolution of $4 \mathrm{~cm}^{-1}$.

\section{ANTIMICROBIAL ACTIVITY}

Using sterile technique, $1 \mathrm{ml}$ of mixed microorganism culture suspension was transferred to a sterile Petri dishes containing previously prepared nutrient agar. The disc samples of bilayer PE/PCL films, $1 \mathrm{~cm}$ in diameter, were applied on the substrate basis. Petri dishes were placed in an inverted position in the thermostat to incubation at temperature of $37{ }^{\circ} \mathrm{C}$ for 48 hours. Antimicrobial activity was measured as width of the inhibition ring around the sample of material (the area without microbial growth).

\section{TG ANALYSIS}

Thermogravimetric analysis (TGA) of studied samples was carried out using TA Instruments Q500 analyzer. The results were obtained for the temperature range from $25^{\circ} \mathrm{C}$ to 550 ${ }^{\circ} \mathrm{C}$ at heating rates of $10^{\circ} \mathrm{C} / \mathrm{min}$ under the flowing of nitrogen or oxygen (air) atmosphere. A constant flow rate of 60 $\mathrm{ml}$ was used during analysis. The residual nanocomposites yield was determined along with the temperature at which 5 mass $\%$ of the sample was decomposed $\left(T_{95}\right)$, the temperature at the maximum degradation rate $\left(T_{\max }\right)$, the maximum degradation rate $\left(v_{\max }\right)$ and the char residue $\left(m_{\mathrm{r} 550^{\circ} \mathrm{C}}\right)$.

\section{RESULTS AND DISCUSSION}

\section{Water Vapour Permeability}

Water vapour transport through polymeric packaging materials or membranes is of great importance for maintenance of food quality and for extending the food products shelf-life. Water vapour transport in the case of polymer material is affected by the thickness of the polymer and by humidity of the surroundings. ${ }^{[11,12]}$ In order to obtain such polymer materials with optimal water vapour permeability for packaging of particular food it is important to adjust barrier properties of common polymer materials by incorporation of different additive types. ${ }^{[13,14]}$ The possibility to improve the barrier performance of food polymer packaging by the application of nanocomposites is a very attractive approach and demands good knowledge about permeability, nanotechnology and influence of different substances. There necessarily must be taken into consideration the main factors affecting the permeability related to both polymer and nanosubstances: level of the dispersion, degree of crystallinity and mobility of polymer chains.[15] When there is a need for preservation of food against water loss (for example meat) polymer packaging material can be modified in order to decrease water vapour permeability to atmosphere. In this study the layer of PCL containing $\mathrm{ZnO}$ or $\mathrm{ZnO} /$ casein is applied on main polymer material (LDPE) and thus are obtained double (bilayer) films. Results of water vapour permeability are given in Table 2 . There can be seen that pure PE polymer has the highest water vapour 
Table 2. Water vapour permeability of the studied samples

\begin{tabular}{lc}
\hline Sample & $g / \mathrm{m}^{2}$ day \\
\hline PE & 28.0 \\
PE/PCL & 19.6 \\
PE/PCL-Zn 1 & 31.1 \\
PE/PCL-Zn 5 & 24.7 \\
PE/PCL-Zn 10 & 14.1 \\
PE/PCL-C-Zn 1 & 28.5 \\
PE/PCL-C-Zn 5 & 26.1 \\
PE/PCL-C-Zn 10 & 14.6 \\
\hline
\end{tabular}

permeability. Some samples prepared with additives have the lower water vapour permeability. The increasing amount of $\mathrm{ZnO}$ in PCL layer contributes to decrease of water loss. It can be seen for both samples, which contain 10 mass \% of ZnO (PE/PCL-Zn 10 and PE/PCL-C-Zn 10) that the water loss is decreased for $50 \%$ in comparison to the sample of pure PE. ZnO is a material with a partly ionic and partly covalent character. Water plays a significant role in many important processes taking place on the $\mathrm{ZnO}$ surface. It is still difficult to identify if water is adsorbed molecularly or dissociatively. ${ }^{[16]}$ It was found that the dissociative adsorption of water is common mechanism. The adsorption of water vapour on $\mathrm{ZnO}$ can be explained by the premise that $\mathrm{H}_{2} \mathrm{O}$ molecule is dissociatevely adsorbed on zinc oxide at all temperatures in the form of $\mathrm{OH}^{\circ}$ and $\mathrm{H}^{*}$ radicals. The adsorption of $\mathrm{OH}^{-}$radical takes place on a $\mathrm{Zn}^{+}$site on a zinc oxide surface. The unpaired electron on $\mathrm{OH}^{-}$radical combines with free electron associated with $\mathrm{Zn}^{+}$site, which results in a strong nonpolar bond.. ${ }^{[17]}$ Due to such water adsorption the samples containing $\mathrm{ZnO}$ show lower water vapour permeability. Such lowered water permeability is especially important for packaging of food like meat, fruit and vegetables because packaging with low water permeability ensures the prolonged freshness of food. If the water loss is expressed as the loss per the area of $1 \mathrm{dm}^{2}$, which is the area of one average food packaging, it is about 0.14 $\mathrm{g} / \mathrm{dm}^{2}$ day for the samples PE/PCL-Zn 10 and PE/PCL-C-Zn 10 , which is very good property and makes this material a good choice for food packaging when low water loss from packaging is favourable.

\section{Scanning Electron Microscopy}

The structure of polymer nanocomposites has strong influence on the material properties and for that reason it is highly important to study and understand the mechanism of its formation. ${ }^{[18]}$ The distribution of the particles mainly depends on the interactions of the components in composite. Analysis of the structure of prepared PE/PCL nanocomposites with zinc and/or casein is shown in Figures 1a) to 1f). Figure 1a), which represents the morphology for the sample $P E / P C L-Z n 1$, shows rough morphology, without fine dispersion of $\mathrm{ZnO}$ particles in PCL. ZnO aggregates are sized
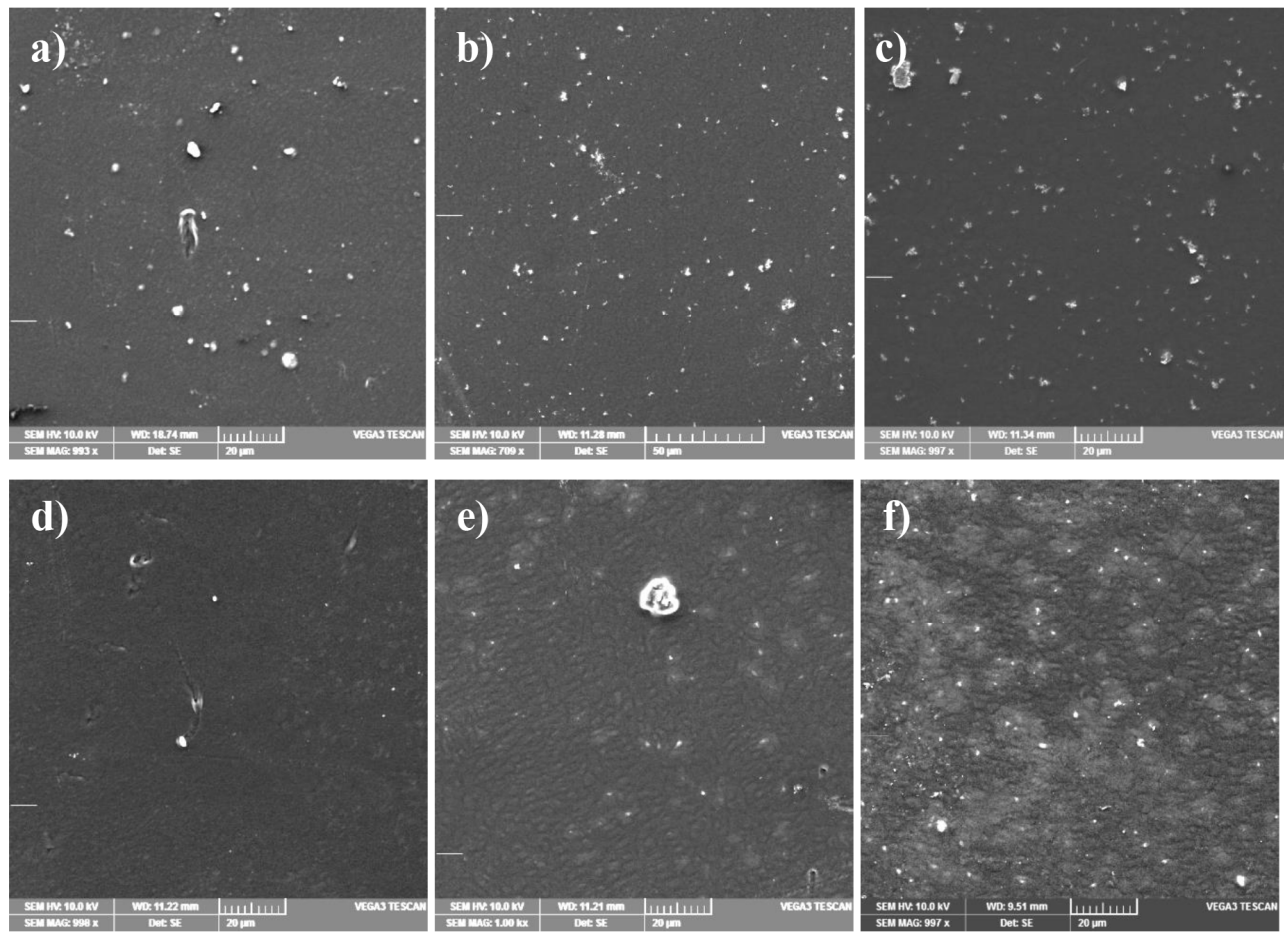

Figure 1. SEM micrographs of bilayer PE/PCL films: a) PE/PCL-Zn1, b) PE/PCL-Zn 5, c) PE/PCL-Zn 10, d) PE/PCL-C-Zn1, e) PE/PCLC-Zn5, f) PE/PCL-C-Zn10. 

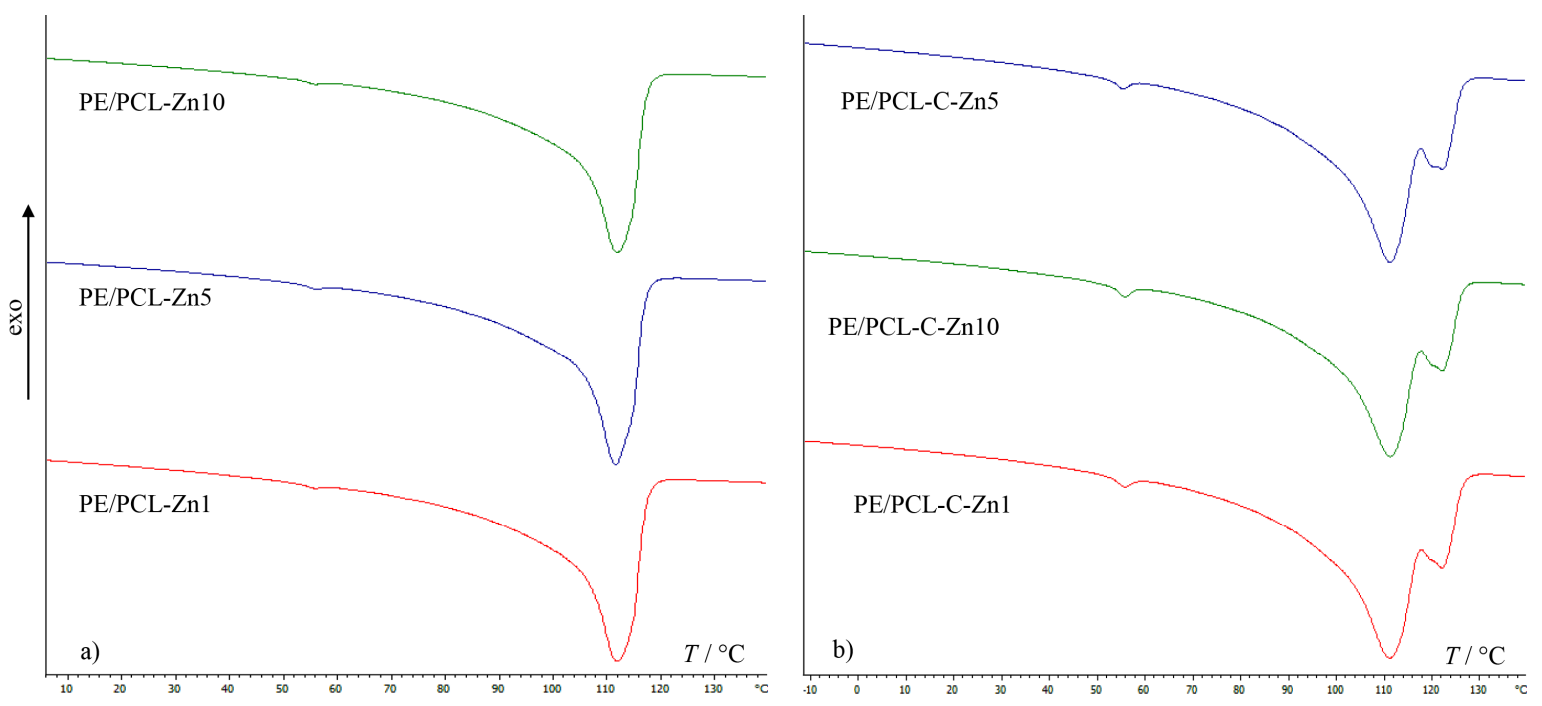

Figure 2. DSC melting endotherms of PE/PCL bilayer films: a) with $\mathrm{ZnO}$ and b) with $\mathrm{ZnO} /$ casein.

from 1 to $4 \mu \mathrm{m}$. Dispersion of particles is a critical parameter, which highly influences material properties because aggregation of additives may cause fracture of polymer material and the decrease of its mechanical and other properties. ${ }^{[19]}$ The distribution of filler in polymer matrix is very important parameter, which has influence on the nanocomposite mechanical properties because the filler particles, their specific surface area and dispersion influence the composite structure and its final properties. ${ }^{[20]}$ For the sample PE/PCL-Zn-5, Figure 1b), it can be seen that this sample shows more uniform morphology without larger aggregates. Sample PE/PCL-Zn-10 shows even better distribution of filler in polymer matrix. The other group of samples, which contains casein, shows diminished level of filler aggregation. Such improved morphology of the samples, especially for the sample $P E / P C L-C / Z n-10$, Figure $1 \mathrm{f}$ ), is considered to be the consequence of the addition of organic component (casein) to inorganic filler $\mathrm{ZnO}$. Adding of casein will contribute to better dispersion of filler particles in PCL polymer matrix (organic component). It can be concluded that it is very important to ensure the lowest possible aggregation of additives in polymer matrix. Low level of aggregations reduces the possibility of formation of weak points in material. In that case the strains in material are lowered and the progression of cracks and grooves at the polymer surface is prevented. Otherwise, fractures on the composite surface or in material bulk could lead to material defects and profoundly influence the mechanical properties of material.[21,22]

\section{DSC Analysis}

Thermal properties and phase behaviour of PE/PCL bilayer films were characterized using DSC. All DSC curves and their presented characteristics are from the second heating and cooling cycle in order to erase the thermal history of the samples. The results are given in Figures 2 and 3 and in Tables 3 and 4 . Melting behaviour of the samples with $\mathrm{ZnO}$ is shown in Figure 2a. It can be seen that at about $55{ }^{\circ} \mathrm{C}$ there is a small endothermic peak representing the melting point of PCL while at about $111{ }^{\circ} \mathrm{C}$ a more intense peak occurs as melting point of $\mathrm{PE}$ polymer. For $\mathrm{PE} / \mathrm{PCL}$ nanocomposites bilayer films with bionanocomplex (Figure $2 b$ ) there can be noticed the occurrence of a new endothermic peak at about $120^{\circ} \mathrm{C}$ with the previous two peaks at $55^{\circ} \mathrm{C}$ and at $111^{\circ} \mathrm{C}$. Possible explanation is that this new peak is present due to the loss of water from the structure of casein because the casein is protein of micellar structure that is rich with water and orthophosphate complexes. When casein is heated, water comes out at temperature interval from $60^{\circ} \mathrm{C}$ to 140 ${ }^{\circ} \mathrm{C} .{ }^{[23]}$ But the appearance of a new peak in samples with bionanocomplex can be seen also with the cooling process, which is shown as exothermic peaks of crystallization (Figure $3 b)$. This indicates the influence of bionanocomplex on the crystal structure of PE since the water of casein lost from its structure during heating cannot be returned by cooling. Furthermore, it is known that fillers in polymer composites can induce the new crystal structures and crystals of various sizes, which consequently leads to the appearance of new peaks in thermograms. ${ }^{[24]}$ Thus, in all studied samples another small peak at about $60{ }^{\circ} \mathrm{C}$ can be noticed. As all the samples contain nanoparticles of zinc oxide that peak is result of formation of a new crystal structure due to their presence while the peak at $105^{\circ} \mathrm{C}$ appears due to the influence of bionanocomplex on PE crystallinity. Therefore, the smallest exothermic peak at $28-29^{\circ} \mathrm{C}$ is seen as crystallinity of $\mathrm{PCL}$, which is a very small peak because the PCL polymer is present in a very low concentrations since it was applied as a thin coating layer, Table 3. 
Table 3. Melting temperature $\left(T_{m}\right)$ and crystallization temperature $\left(T_{c}\right)$ of PE and PE/PCL bilayer films

\begin{tabular}{ccccc}
\hline Sample & $T_{\mathrm{m} 1 \text { (PCL) }} /{ }^{\circ} \mathrm{C}$ & $T_{\mathrm{m} 2 \text { (PE) }} /{ }^{\circ} \mathrm{C}$ & $T_{\mathrm{c} 1 \text { (PCL) }} /{ }^{\circ} \mathrm{C}$ & $T_{\mathrm{c2} \text { (PE) }} /{ }^{\circ} \mathrm{C}$ \\
\hline PE & - & 109.7 & - & 97.2 \\
PE/PCL & 50.6 & 107.4 & 29.2 & 94.7 \\
PE/PCL-Zn 1 & 55.8 & 112.1 & 28.5 & 96.8 \\
PE/PCL-Zn 5 & 56.0 & 111.6 & 28.2 & 97.3 \\
PE/PCL-Zn 10 & 55.7 & 111.9 & 29.0 & 96.8 \\
PE/PCL-C-Zn 1 & 55.6 & 111.2 & 28.5 & 97.1 \\
PE/PCL-C-Zn 5 & 55.1 & 111.2 & 28.8 & 97.4 \\
PE/PCL-C-Zn 10 & 55.7 & 111.2 & 28.7 & 97.3 \\
\hline
\end{tabular}

Table 4. Melting enthalpy $\left(\Delta H_{m}\right)$ and enthalpy of crystallization $\left(\Delta H_{c}\right)$ of PE and PE/PCL bilayer films

\begin{tabular}{ccccc}
\hline Sample & $\Delta H_{\mathrm{m} 1 \text { (PCL) }} / \mathrm{J} \mathrm{g}^{-1}$ & $\Delta H_{\mathrm{m} 2(\mathrm{PE})} / \mathrm{J} \mathrm{g}^{-1}$ & $\Delta H_{\mathrm{c1}(\mathrm{PCL})} / \mathrm{J} \mathrm{g}^{-1}$ & $\Delta H_{\mathrm{cz} \text { (PE) }} / \mathrm{J} \mathrm{g}^{-1}$ \\
\hline PE & - & 96.3 & - & 123.5 \\
PE/PCL & 0.4 & 80.7 & 0.6 & 108.1 \\
PE/PCL-Zn 1 & 0.4 & 94.6 & 0.5 & 124.6 \\
PE/PCL-Zn 5 & 0.4 & 94.4 & 0.5 & 120.6 \\
PE/PCL-Zn 10 & 0.3 & 98.6 & 0.4 & 111.5 \\
PE/PCL-C-Zn 1 & 1.0 & 110.3 & 1.1 & 127.7 \\
PE/PCL-C-Zn 5 & 0.8 & 103.8 & 1.0 & 123.9 \\
PE/PCL-C-Zn 10 & 1.0 & 89.3 & 1.4 & 113.2 \\
\hline
\end{tabular}

From the values of melting enthalpy $\left(\Delta H_{\mathrm{m}}\right)$ and enthalpy of crystallization $\left(\Delta H_{c}\right)$ of PE/PCL bilayer films, Table 4 , it can be observed that the melting enthalpy of polyethylene samples with casein bionanocomplex is lowered (110 to $89 \mathrm{~J} \mathrm{~g}^{-1}$ ) as the amount of $\mathrm{ZnO}$ nanoparticles is increasing. Similar behavior can be seen from the polyethylene crystallization enthalpy for the samples with bionanocomplex since its values are lowered from 128 to $113 \mathrm{~J} \mathrm{~g}^{-1}$, and for the samples without bionanocomplex from about 125 to about $112 \mathrm{~J} \mathrm{~g}^{-1}$. This indicates that the addition of $\mathrm{ZnO}$ nanoparticles and bionanocomplex reduces the fraction of crystalline phase in polyethylene polymer. Although, it is observed that a new, additional crystalline fraction is formed (due to the appearance of new peaks). The size of
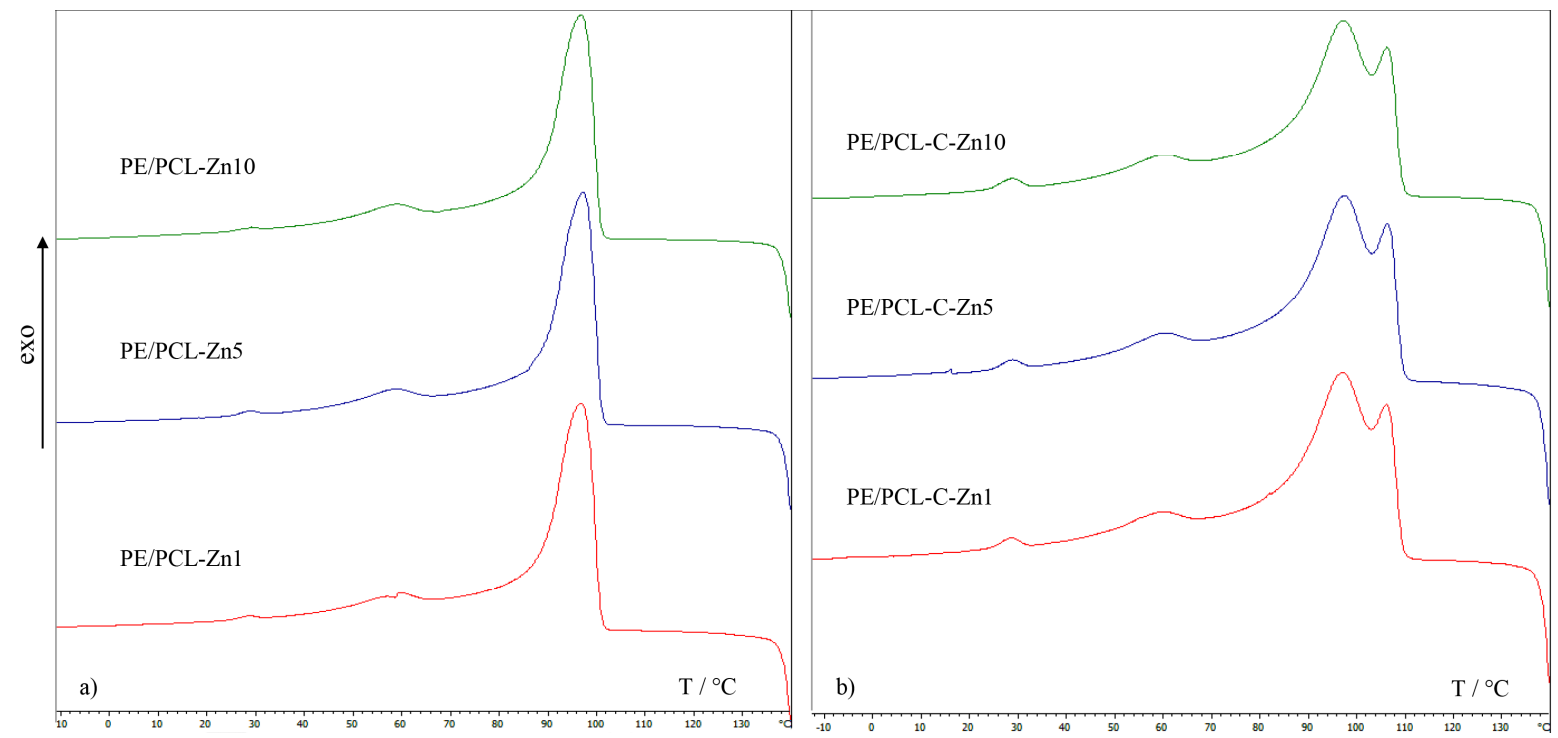

Figure 3. DSC crystallization behaviour of PE/PCL bilayer films: a) with $\mathrm{ZnO}$ and b) with $\mathrm{ZnO} /$ casein. 


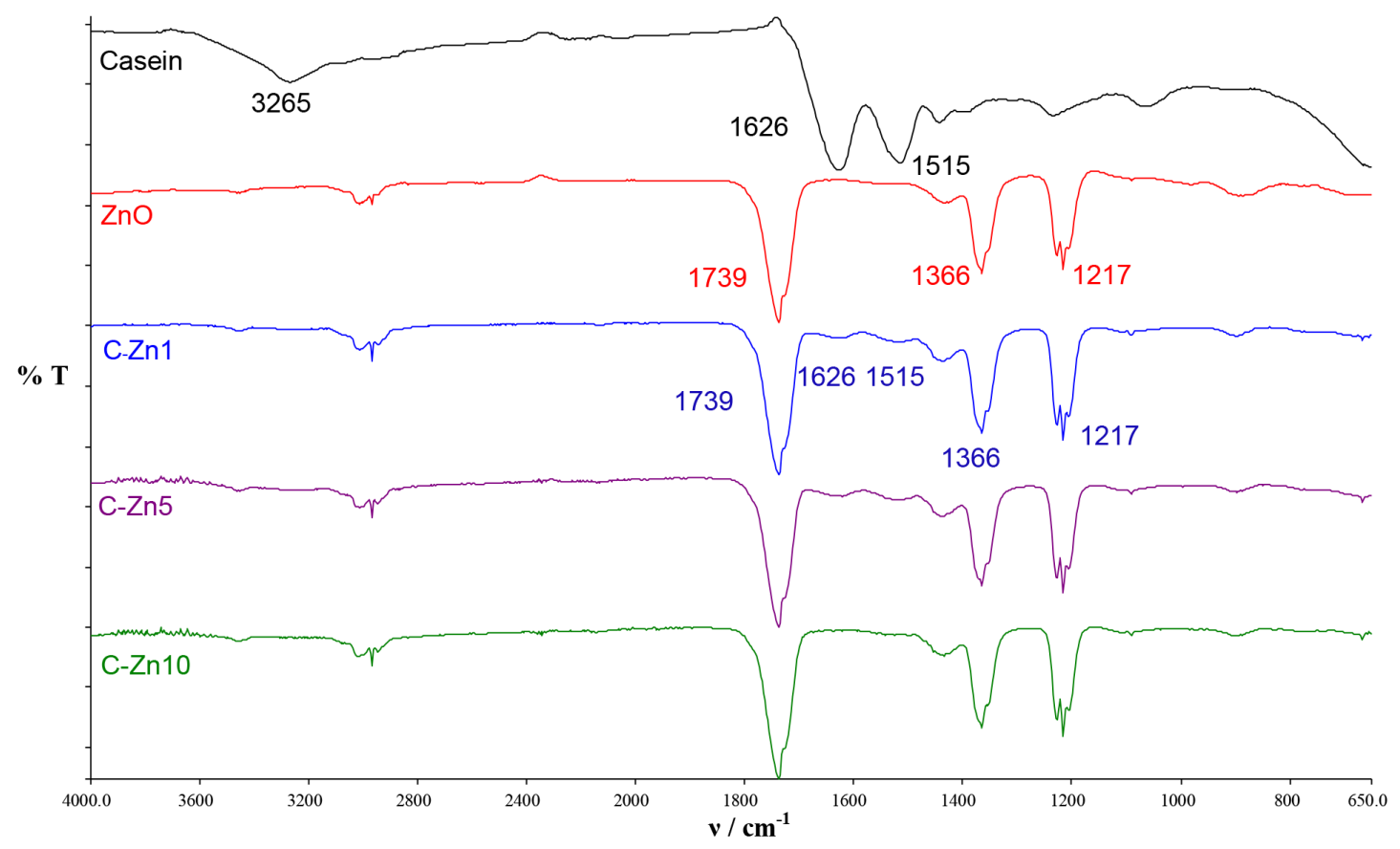

Figure 4. FTIR spectrograms of pure casein, $\mathrm{ZnO}$ and $\mathrm{ZnO} /$ casein complexes.

such crystals is small and thus reduces overall crystallinity of $\mathrm{PE}$ polymer, which then has a considerable effect on the mechanical properties of the PE/PCL bilayer films.

\section{FTIR Analysis}

$\mathrm{PE} / \mathrm{PCL}$ bilayer films with added $\mathrm{ZnO}$ and $\mathrm{ZnO}$ /casein were characterized by FTIR spectroscopy and identification of pure casein and pure $\mathrm{ZnO}$ nanoparticles was also carried out (Figures 4 and 5). All films were recorded from PCL coating side. At FTIR spectrum of pure $\mathrm{ZnO}$ nanoparticles three clearly expressed peaks at 1738,1365 and $1217 \mathrm{~cm}^{-1}$ are visible. These peaks are not a direct consequence of $\mathrm{ZnO}$ structure and have already been residual impurities from the synthesis of nano-ZnO, which is carried out over zinc salts, usually zinc acetate. Thus, the peak at $1738 \mathrm{~cm}^{-1}$ is attributed to bond stretching of the carbonyl (CO) group and a peak at $1217 \mathrm{~cm}^{-1}$ indicates the acetate group ${ }^{[25]}$ while the peak at $1365 \mathrm{~cm}^{-1}$ appears due to the presence of $\mathrm{C}-\mathrm{H}$ bonds. ${ }^{[26]}$ The vibration of $\mathrm{Zn}-\mathrm{O}$ bond is located at the wavelength of $450 \mathrm{~cm}^{-1}[27]$ and it can not be seen at this spectra because it is located outside the measuring range of this FTIR spectrometer, so it could not be detected.

Casein characteristic vibration bands are found in the "fingerprint" region that is located in the area of 1800-800 $\mathrm{cm}^{-1}$ as in this area the absorption of amide groups (CO, NH and $\mathrm{CN}$ ) is occurring due to the complex structure of protein. ${ }^{[28]}$ The two most important amide types are the amide I where vibrations are caused by the bond stretching of $\mathrm{C}=\mathrm{O}$, and amide II where vibration are caused by the bond deformation of the $\mathrm{N}-\mathrm{H}$ and stretching of $\mathrm{C}-\mathrm{N}$ bond. The vibration of amide I bond occurs in the area of 1700-1600 $\mathrm{cm}^{-1}$ while the amide II vibration is seen in the region from 1600 to $1500 \mathrm{~cm}^{-1}$. ${ }^{[29]}$ The exact wavelengths at which these bonds absorb infrared radiation depend on the secondary structure of proteins or peptides. ${ }^{[30]}$ In the FTIR spectrum of pure casein these vibrations are visible at $1625 \mathrm{~cm}^{-1}$ and $1515 \mathrm{~cm}^{-1}$, Figure 4 . The broad peak at $3265 \mathrm{~cm}^{-1}$ indicates the stretching of the hydroxyl $(\mathrm{OH})$ groups of the water that is present in the composition of the casein. $\mathrm{C} / \mathrm{Zn} 1$ sample shows the vibrations for both $\mathrm{ZnO}$ and casein. $\mathrm{C} / \mathrm{Zn} 10$ sample, which contains the highest proportion of $\mathrm{ZnO}$ nanoparticles, has the least pronounced vibrations of casein (at 3265,1625 and $1515 \mathrm{~cm}^{-1}$ ).

In all samples of bilayer films with bionanocomplex (PE/PCL/C/Zn1, PE/PCL/C/Zn5 and PE/PCL/C/Zn10) the vibrations at 1738,1365 and $1217 \mathrm{~cm}^{-1}$ are present and correspond to pure $\mathrm{ZnO}$ while vibrations at 1625 and 1515 $\mathrm{cm}^{-1}$ are characteristic for casein and are hardly visible because casein is present in the PCL coating in a very low concentration, Figure 5.

\section{Mechanical Properties}

The mechanical properties, tensile strength and elongation of studied PE/PCL bilayer films are shown in Table 5. For the samples PE/PCL/Zn-5 and PE/PCL/Zn-10, prepared with zinc oxide, it can be seen that $\mathrm{ZnO}$ nanoparticles in the samples affect the decrease of tensile strength and elongation in comparison to pure PE. On contrary, the sample PE/PCL/Zn- 


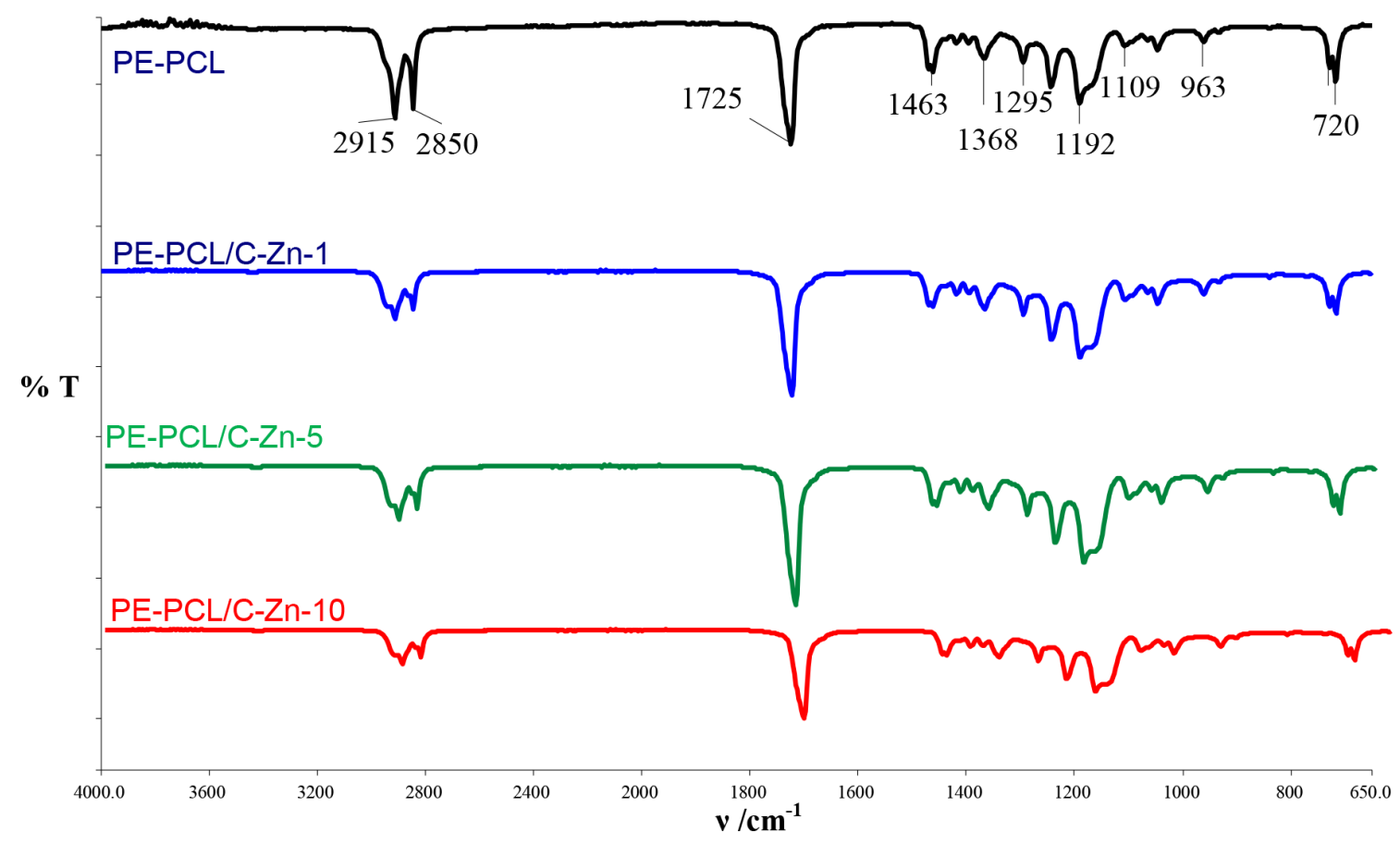

Figure 5. FTIR spectrograms of bilayer films PE/PCL, PE/PCL-C-Zn1, PE/PCL-C-Zn5 and PE/PCL-C-Zn 10.

1 shows some improvement of mechanical properties compared to the pure PE and pure PE/PCL film. This indicates that small amount of nanoparticles is well dispersed in a matrix of PCL resulting in an increase of the mechanical properties while the addition of higher portion of nanoparticles causes their weakening.

Furthermore, the study of mechanical properties of $\mathrm{PE} / \mathrm{PCL}$ bilayer films that contain casein bionanocomplex indicates that the addition of casein bionanocomplex significantly improves the mechanical properties compared to films with $\mathrm{ZnO}$ nanoparticles. The values of tensile strength and elongation indicate that significantly higher homogeneity has been obtained and that the dispersion of $\mathrm{ZnO}$ nanoparticles in casein and PCL matrix is very good. Thus, it is evident that tensile strength of all samples $\mathrm{PE} / \mathrm{PCL} / \mathrm{C} / \mathrm{Zn}$ is approximately $19 \mathrm{~N} / \mathrm{mm}^{2}$ which

Table 5. Tensile strength $(\sigma)$ and elongation at break $(\varepsilon)$ of PE and PE/PCL bilayer films

\begin{tabular}{ccc}
\hline Sample & $\sigma_{\mathrm{R}} /\left(\mathrm{N} \mathrm{mm}^{-2}\right)$ & $\varepsilon_{\mathrm{R}} / \%$ \\
\hline PE & $12.9 \pm 1.5$ & $533 \pm 47$ \\
PE/PCL & $11.9 \pm 1.3$ & $471 \pm 16$ \\
PE/PCL-Zn 1 & $14.7 \pm 0.9$ & $565 \pm 38$ \\
PE/PCL-Zn 5 & $12.3 \pm 1.7$ & $526 \pm 23$ \\
PE/PCL-Zn 10 & $10.3 \pm 0.9$ & $469 \pm 47$ \\
PE/PCL-C-Zn 1 & $19.2 \pm 1.0$ & $815 \pm 78$ \\
PE/PCL-C-Zn 5 & $19.4 \pm 0.9$ & $842 \pm 81$ \\
PE/PCL-C-Zn 10 & $19.3 \pm 0.8$ & $851 \pm 47$ \\
\hline
\end{tabular}

represents the increase of $60 \%$ compared to pure $\mathrm{PE} / \mathrm{PCL}$ film $\left(11.9 \mathrm{~N} / \mathrm{mm}^{2}\right)$. Furthermore, the elongation for the samples with casein bionanocomplex shows an increase of approximately $70 \%$ in comparison to $\mathrm{PE} / \mathrm{PCL}$ film and is growing further with increase of nanoparticles portion, from $815 \%$ to $851 \%$. Since the mechanical properties are significantly increased, it is concluded that the interaction between PE carrier film and casein bionanocomplex dispersed in PCL coating has been established, which is explained by DSC analysis that shows significant decrease in crystallinity.

The mechanical properties of filled polymers are difficult to predict because they are very dependent on local interactions between polymers and particles/fillers. An interface between polymer-filler usually acts as a "weakening point" in the material and thus causing its premature breakage or tearing (cracking). The weakening of the mechanical properties is interpreted as a lack of miscibility of particles with polymer matrix in the absence of the favourable thermodynamics. It is known that when the polymer-inorganic particles adhesion is very good, the stress is much more effectively transferred from the polymer matrix to the inorganic particles and thus the mechanical properties were enhanced. ${ }^{[31]}$ When the lack of interactions is present, the mechanical properties additionally significantly depend on the processing conditions. Vice versa, when strong interactions exist in the composite the composite is not affected by processing conditions (extrusion, dissolution). ${ }^{[32]}$ According to the 

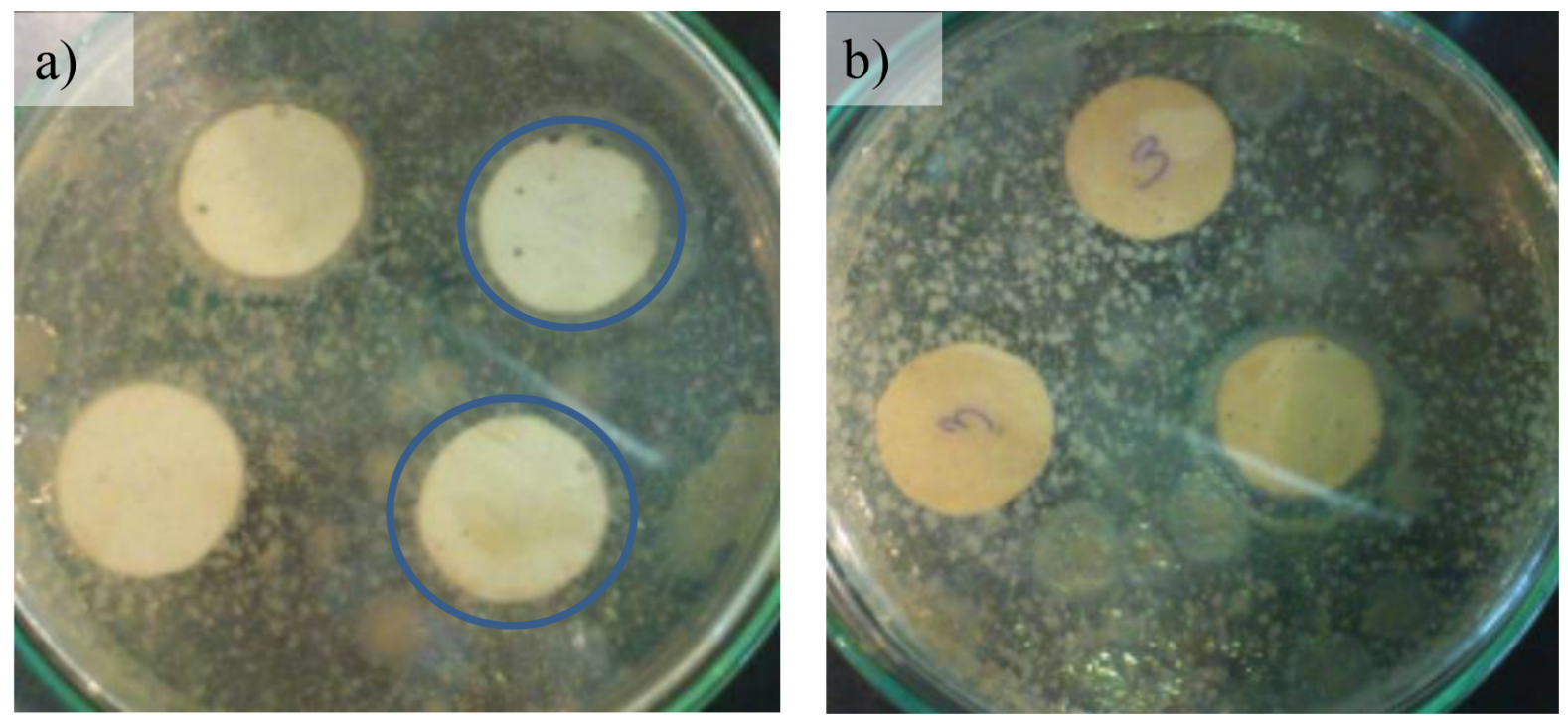

Figure 6. Microbial growth for the samples: a) PE/PCL/Zn-5 i b) PE/PCL/Zn-10.

results, it is evident that $\mathrm{PE} / \mathrm{PCL}$ bilayer films have good mechanical properties and that the coating layer of $\mathrm{PCL}$ adheres to the PE carrier film without any occurrence of their delamination.

\section{Antimicrobial Activity}

In recent times the use of nanoparticles for antibacterial purposes is constantly increasing. The active substance ensures a high protection against food spoilage during food transport, storage and shelf-life. ${ }^{[2,33]}$ The emphasis in formulation of antimicrobial agents is given mostly to the types of safe and nontoxic biocidal substances. ${ }^{[34]}$ The nanoparticles possess unique chemical, physical and biological properties, due to their small dimensions, which can be used for many desired applications. Because of their high surface-to-volume ratio they are particularly effective as antimicrobial agents. Such enlarged surface enables them to deactivate microorganisms more effectively than microcomposites. ${ }^{[35]}$

Some metals and metal oxides are commonly used as antimicrobial agents (silver, titanium dioxide, zinc oxide). Their nanoparticles have the ability to anchor to the bacterial cell wall and penetrate into the cell where influence the structural changes in the cell membrane and its permeability and finally cause bacterial death. ${ }^{[36]}$

Zinc oxide is known for its strong antimicrobial effect on a broad spectrum of microorganisms against both the Gram-positive and Gram-negative bacteria. ${ }^{[37]}$ According to FDA zinc oxide is generally recognised as a safe and nontoxic material for the use in contact with food and cosmetic products and it shows high rate of bacterial growth suppression.
Figure 6 shows the samples of PE/PCL films with zinc oxide where the disc of studied material containing antibacterial substance is placed in a sterile Petri dish with a nutrient agar and a suspension of mixed culture of microorganism. After $48 \mathrm{~h}$ of incubation antibacterial activity is measured as a length of inhibition ring (area around disc of studied material without bacterial growth). Obtained results show that the bacterial growth is lower for the sample with the higher content of $\mathrm{ZnO}(\mathrm{PE} / \mathrm{PCL} / \mathrm{Zn}-10)$, Figure 6b), though the real strong inhibition ring did not occur. It was assumed that the concentration of zinc oxide as an active antimicrobial substance is not high enough to form real inhibition area around the tested polymer material.

\section{TG Analysis}

The effect of additives in PCL coatings on thermal properties of PE/PCL nanocomposites bilayer films in inert $\mathrm{N}_{2}$ and oxidative atmosphere was studied. TG and dTG curves are presented in Figures 7 and 8 . The temperatures at the beginning of decomposition ( $\left.T_{95}\right)$, temperatures at the maximum decomposition rate $\left(T_{\max }\right)$ together with the maximum decomposition rate $\left(v_{\max }\right)$, char residue $\left(m_{\left.\mathrm{r} 550{ }^{\circ} \mathrm{C}\right)}\right.$ and mass loss $\left(\Delta m_{\max }\right)$ at $T_{\max }$ are given in Table 6. Figure 7 suggests that decomposition in inert $\mathrm{N}_{2}$ atmosphere of the all studied films occurs in one major step seen as one maximum at DTG curves while in oxidative atmosphere at least two major maximums are observed, Figure 8 . The curves indicate differences between two mechanisms of decomposition in various atmospheres since oxygen is consumed primarily by gas-phase oxidation reactions during burning of the polymer and oxygen hardly reaches the thermally degrading sample surface beneath the evolved gaseous 


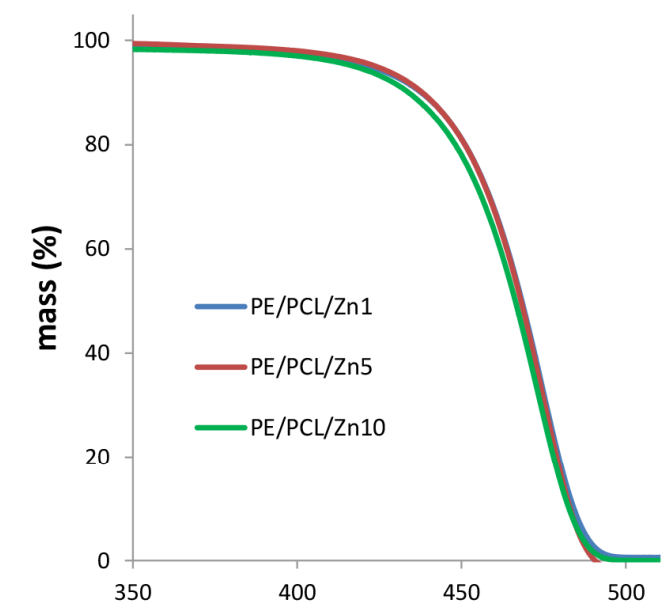

a)

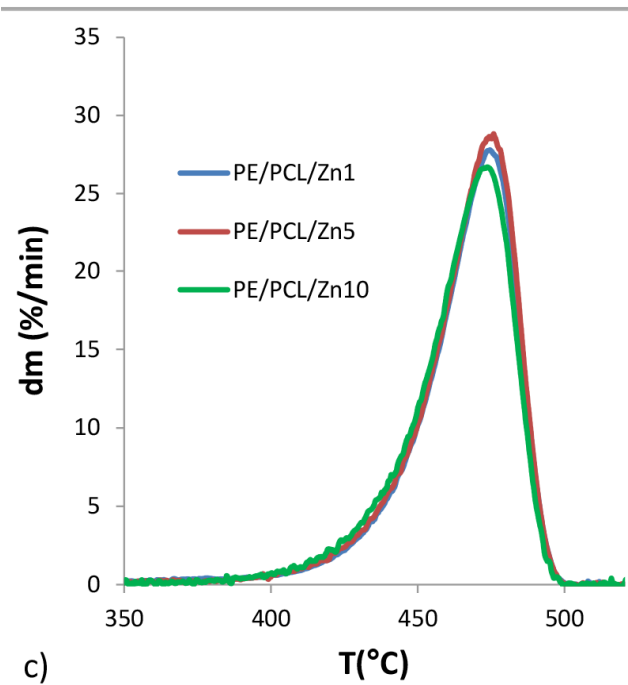

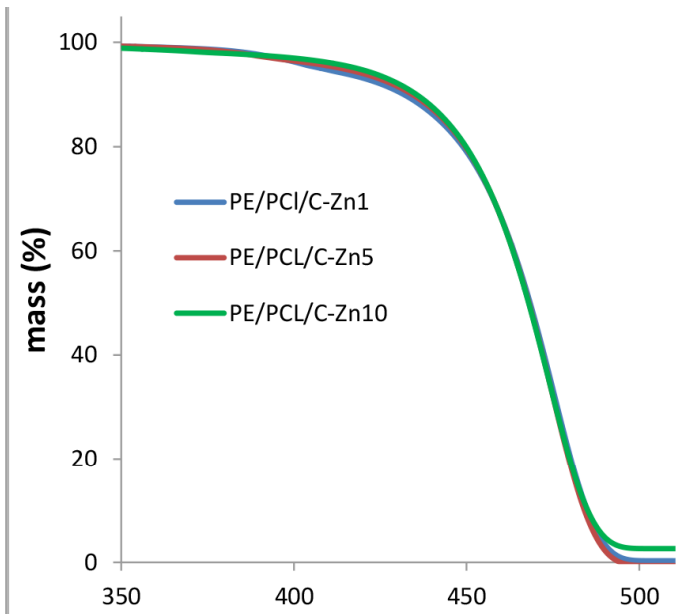

b)

$\mathrm{T}\left({ }^{\circ} \mathrm{C}\right)$

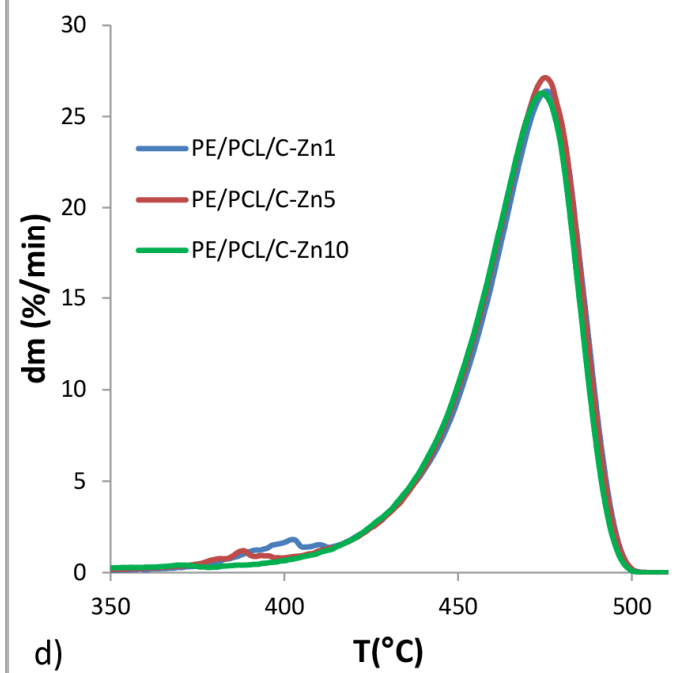

Figure 7. TG and DTG curves of the studied PE/PCL bilayer films under nitrogen flow.

Table 6. Initial decomposition temperature $\left(T_{95}\right)$, temperature at the maximum degradation rate $\left(T_{\max }\right)$, mass loss at $T_{\max }$ $\left(\Delta m_{\max }\right)$, char residue $\left(m_{\mathrm{r} 550^{\circ} \mathrm{C}}\right)$ and maximum degradation rate $\left(v_{\max }\right)$ of PE and PE/PCL bilayer films

\begin{tabular}{cccccccccccc}
\hline \multirow{2}{*}{ Sample } & \multicolumn{2}{c}{$T_{95} /{ }^{\circ} \mathrm{C}$} & \multicolumn{2}{c}{$T_{\max } /{ }^{\circ} \mathrm{C}$} & \multicolumn{2}{c}{$\Delta m_{\max } / \%$} & \multicolumn{2}{c}{$m_{\mathrm{r} 550^{\circ} \mathrm{C} /{ }^{\circ} \mathrm{C}}$} & \multicolumn{3}{c}{$V_{\max } /(\% / \mathrm{min})$} \\
& $\mathrm{N}_{2}$ & $\mathrm{O}_{2}$ & $\mathrm{~N}_{2}$ & $\mathrm{O}_{2}$ & $\mathrm{~N}_{2}$ & $\mathrm{O}_{2}$ & $\mathrm{~N}_{2}$ & $\mathrm{O}_{2}$ & $\mathrm{~N}_{2}$ & $\mathrm{O}_{2}$ \\
\hline PE & 397.2 & 306.1 & 465.9 & 352.8 & 71.2 & 30.9 & 0.6 & 4.0 & 19.0 & 15.4 \\
PE/PCL & 428.0 & 315.0 & 475.9 & 372.0 & 68.5 & 39.2 & 0.0 & 0.3 & 29.7 & 20.2 \\
PE/PCL-Zn 1 & 421.7 & 327.3 & 474.6 & 378.4 & 66.6 & 37.8 & 0.6 & 4.4 & 27.8 & 16.8 \\
PE/PCL-Zn 5 & 424.0 & 331.0 & 475.8 & 386.8 & 71.3 & 33.6 & 0.1 & 5.2 & 28.8 & 22.1 \\
PE/PCL-Zn 10 & 417.4 & 329.0 & 473.8 & 378.4 & 68.8 & 29.9 & 0.1 & 3.1 & 26.7 & 15.0 \\
PE/PCL-C-Zn 1 & 408.0 & 336.5 & 475.5 & 390.2 & 67.8 & 40.3 & 0.3 & 4.2 & 26.4 & 22.1 \\
PE/PCL-C-Zn 5 & 413.8 & 336.2 & 475.1 & 382.2 & 68.3 & 31.9 & 0.1 & 4.7 & 27.1 & 23.6 \\
PE/PCL-C-Zn 10 & 418.3 & 335.3 & 474.0 & 414.6 & 65.3 & 61.4 & 2.7 & 3.5 & 26.3 & 18.4 \\
\hline
\end{tabular}




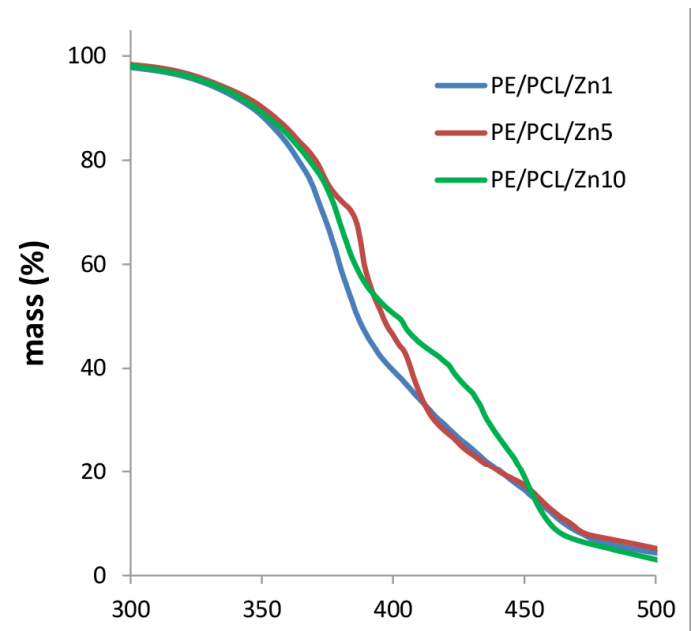

a)

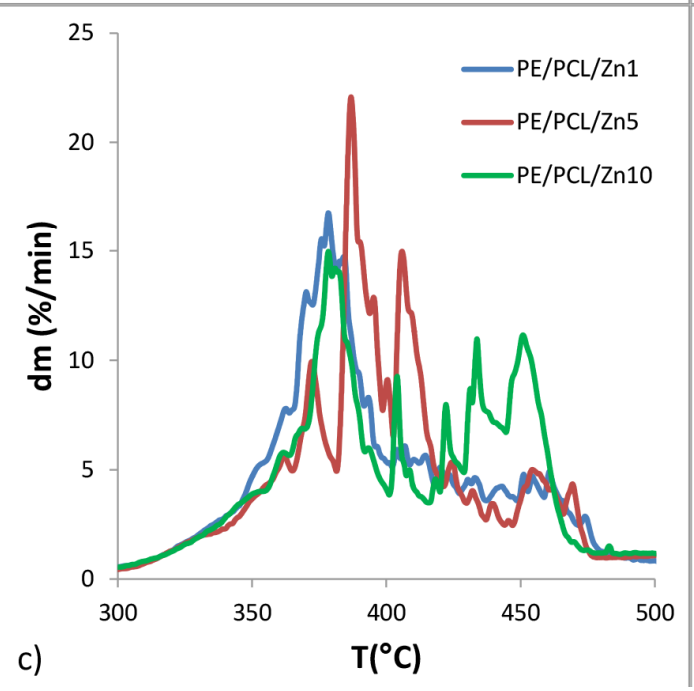

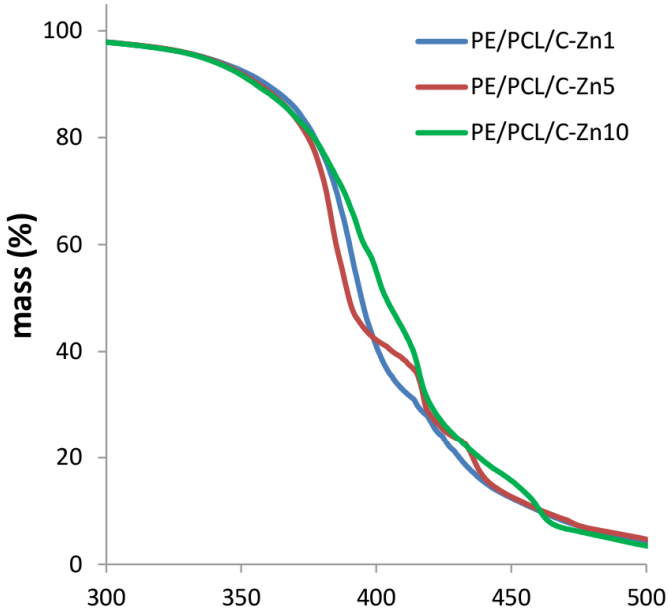

b)

$\mathrm{T}\left({ }^{\circ} \mathrm{C}\right)$

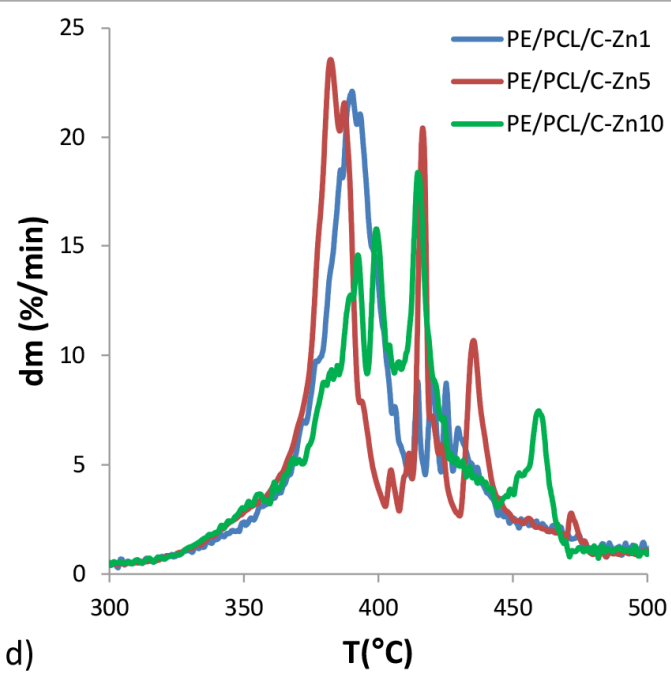

Figure 8. TG and DTG curves of the studied PE/PCL bilayer films under oxygen (air) flow.

products. ${ }^{[38]}$ From the temperatures obtained by process conducted in inert $\mathrm{N}_{2}$ atmosphere it can be seen that the largest contribution to thermal stability of bilayer films comes because of additives in PCL coating, Table 6 and Figure 7. The values of $T_{95}$ and $T_{\max }$ are increased for samples of $\mathrm{PE} / \mathrm{PCL}$ coatings with $\mathrm{ZnO}$ nanoparticles and biocomplex of $\mathrm{ZnO} /$ casein, in comparison to neat $\mathrm{PE}$, because they exhibit reduced $T_{95}$ while $T_{\max }$ remained approximately the same for the all bilayer films. Reduction of $T_{95}$ values is explained by the fact that metal ions in oxides act as catalysts of hydroperoxide decomposition during depolymerisation and thus cause an increase of depolymerisation and degradation. ${ }^{[31]}$ The same trend of behaviour is seen for the maximum degradation rate $\left(v_{\max }\right)$ where can be noticed the first significant increase of value for PE/PCL (29.7\%/min) regarding neat $P E(19 \% / \mathrm{min})$. Then there is a small decrease of values for PE/PCL nanocomposites bilayer films.
On the other hand, considering the decomposition in an $\mathrm{O}_{2}$ atmosphere, opposite behaviour can be seen since the values of $T_{95}$ and $T_{\max }$ are increasing regarding to neat $\mathrm{PE}$ and regarding to neat $\mathrm{PE} / \mathrm{PCL}$ films. Particularly high increase of $T_{\max }$ values is seen for the samples prepared with bionanocomplex in PCL coatings as it can be seen for the samples: PE/PCL-C-Zn10 and PE/PCL-C-Zn1 that are higher for $42^{\circ} \mathrm{C}$ and $18^{\circ} \mathrm{C}$, respectively, in comparison to $\mathrm{PE} / \mathrm{PCL}$. That reveals the higher thermal stability of PE/PCL nanocomposites bilayer films in this atmosphere. Further on, when the maximum degradation rate values in inert and oxygen atmosphere are compared, lower values are those obtained in oxygen atmosphere indicating slower decomposition process. Comparing the char residue it can be seen that small yield is obtained after decomposition in oxygen from $3.1 \%$ to $5.1 \%$ while for the inert decomposition it is approximately zero. It is assumed that in oxygen atmosphere 
the samples show enhanced thermal stability due to higher char yield that is assumed to act as a superior insulator and mass transport barrier to the volatile products generated during decomposition.

The results of the mass loss $\left(\Delta m_{\max }\right)$ at the maximum degradation rate, Table 6 , show significantly lower mass loss in oxygen that is particularly well seen for the samples with $\mathrm{ZnO}$ nanoparticles in $\mathrm{PCL}$ coating. Only $30 \%$ of mass loss is obtained for the sample PE/PCL-Zn10 while at the same time, for the inert atmosphere, mass loss is of $69 \%$.

It can be concluded that the crucial effect on properties (thermal stability as well as the other properties like mechanical properties) of polymer composites has the dispersion of the active component in the polymer matrix, which is influenced by mutual interactions. The particle size and its specific surface area also have important consequences, like the incorporation in the matrix and the level of dispersion, which affect the final properties of the composites. ${ }^{[39]}$

\section{CONCLUSIONS}

The obtained results showed that the incorporation of $\mathrm{ZnO}$ and $\mathrm{ZnO} /$ casein complex into $\mathrm{PCL}$ layer can reduce the permeability of water vapour through PE/PCL packaging films, what is especially seen for the samples PE/PCL-Zn10 and $\mathrm{PE} / \mathrm{PCL}-\mathrm{C}-\mathrm{Zn} 10$. It can be concluded that this material is a good choice for food packaging when low water loss from packaging is favourable.

$\mathrm{PE} / \mathrm{PCL}$ bilayer films that contain $\mathrm{ZnO} /$ casein complex show significantly improved mechanical properties and are the proof that the coating layer of $\mathrm{PCL}$ adheres to the $\mathrm{PE}$ carrier film without any occurrence of delamination.

The sample with the highest content of $\mathrm{ZnO}$ has increased antimicrobial activity.

Overall properties of studied PCL/PE bilayer films show that such packaging material exhibits improved barrier, mechanical and thermal properties due to the addition of active components that can successfully protect food products during their transport and shelf-life.

Acknowledgment. This work was financially supported by University of Zagreb, Croatia, in 2013./2014., through the Research Project 110002.

\section{REFERENCES}

[1] C. E. Realini, B. Marcos, Meat Sci. 2014, 98, 404.

[2] J. H. Han, Food Technol-Chicago 2000, 54(3), 56.

[3] L. Vermeiren, F. Devlieghere, M. van Beest, N. de Kruijf, J. Debevere, Trends Food Sci. Tech. 1999, 10(3), 77.

[4] M. Ozdemir, J. D. Floros, Crc Cr. Rev. Food Sci. 2004, 44(3), 185.
[5] S. Alix, A. Mahieu, C. Terrie, J. Soulestin, E. Gerault, M. G. J. Feuilloley, R. Gattin, V. Edon, T. Ait-Younes, N. Leblanc, Eur. Polym. J. 2013, 49, 1234.

[6] G. W. P. Arora, J. Food. Sci. 2010, 75, 9.

[7] C. Silvestre, D. Duraccio, S. Cimmino, Prog. Polym. Sci. 2011, 36, 1766.

[8] H. M. C. De Azeredo, Food Res. Int. 2009, 42, 1240.

[9] A. Llorens, E. Lloret, P. A. Picouet, R. Trbojevich, A. Fernandez, Trends Food Sci. Tech. 2012, 24, 19.

[10] J. W. Rhim, P. Hwan-Man, H. Chang-Sik, Prog. Polym. Sci. 2013, 38, 1629.

[11] C. Andersson, Packag. Technol. Sci. 2008, 21(6), 339.

[12] J. Kuusipalo, K. Lahtinen, Tappi J. 2008, 7, 8.

[13] S. D. F. Mihindukulasuriya, L.-T. Lim, Trends Food Sci. Tech. 2014, 40, 149.

[14] S. Farris, L. Introzzi, L. Piergiovanni, Packag. Tech. Sci. 2009, 22, 69.

[15] F. Johansson, A. Leufv'en, Food Packaging Polymer Asbarrier against Aroma Vapour and Oxygen in Fat or Humid Environments, in: P. Ackermann, M. Tagerstand, T. Ohesson, (Eds.) Food and Packaging Materials: Chemical Interactions, The Royal Society of Chemistry, Cambrige, UK, 1995.

[16] D. Raymand, A. C. T. van Duin, D. Spångberg, W. A. Goddard III, K. Hermansson, Surf. Sci. 2010, 604, 741.

[17] G. Sengupta, H. S. Ahluwalia, S. P. Sen, Proceedings of the Indian National Science Academy, 1975, 41(Part A), 102.

[18] P. Pötschke, K. Wallheinke, H. Fritsche, H. Stutz, J. Appl. Polym. Sci. 1997, 64, 749.

[19] J. Cayer-Barrioz, L. Ferry, D. Frihi, K. Cavalier, R. Seguela, G. Vigier, J. Appl. Polym. Sci. 2006, 100, 989.

[20] H. Ishida, S. Campbell, J. Blackwell, Chem. Mater. 2000, 12, 1260.

[21] R. L. Oréfice, J. Braz. Soc. Mech. Sci. 2001, 23(1), 1.

[22] M. E. Mackay, A. Tuteja, P. M. Duxbury, C. J. Hawer, B. Van Horn, Z. B. Guan, G. H. Chen, R.S. Krishanan, Science 2006, 311, 1740.

[23] R. R. Schrieke, G. Winter, Casein, in: H. M. Mark, N. M. Bikales, C. G. Overberger, G. Mendes (Eds.), Encyclopedia of Polymer Science and Engineering, Vol. 2, Wiley-Interscience Publication, John Wiley\&Sons, New York, 1985, pp. 685-691.

[24] R. N. Rothon, Particulate-filled Polymer Composites, Rapra Technology Ltd., Shrewsbury, UK, 2003, p. 36.

[25] L. E. Greene, Angew. Chem. Int. Ed. 2003, 42, 3031.

[26] J. Scheirs, Compositional and Failure Analysis of Polymers: A Practical Approach, John Wiley \& Sons, New York, 2000, p. 158.

[27] Z. R. Khan, M. S. Khan, M. Zulfequar, M. S. Khan, Mater. Sci. Appl. 2011, 2, 340.

[28] A Jowder, M. Defernez, E. K. Kemsley, R. H. Wilson, J. Agric. Food Chem. 1999, 47, 3210. 
[29] D. Curley, T. Kumosinski, J. Unrah, H. Farrell, J. Dairy Sci. 1998, 81, 3154.

[30] T. F. Kumosinski, H. M. Farrell, Trends Food Sci. Tech. 1993, 4, 169.

[31] A. B. Morgan, C. A. Wilkie, Flame Retardant Polymer Nanocomposites, John Wiley\&Sons, New Jersey, 2007, p. 318.

[32] M Ataeefard, S. Moradian, Polym.-Plast. Technol. 2011, 50(7), 732.

[33] S. Quintavalla, L. Vicini, Meat Sci. 2002, 62(3), 373.

[34] P. Kanmani, J.-W. Rhim, Nano and Nanocomposite Antimicrobial Materials for Food Packaging
Applications, in: J.-W. Rhim (Ed.), Progress in Nanomaterials for Food Packaging, Future Science Ltd., London, UK, 2014, pp. 34-48.

[35] T. V. Duncan, J. Colloid Interf. Sci., 2011, 363, 1.

[36] M. Palomba, G. Carotenuto, L. Cristino, M.A. di Grazia, F. Nicolais, S. de Nicola, J. Nanomater. 2012, 1.

[37] J. Sawai, T. Yoshikawa, J. Appl. Microbiol. 2004, 96(4), 803.

[38] D. Baral, P. P. De, G. B. Nando, Poly. Degrad. Stab. 1999, 65, 47.

[39] D. M. Lincoln, R. A. Vaia, Z. G. Wang, B. S. Hsiao, Polymer 2001, 42, 1621. 